\title{
Mesosynthesis of ZnO-Silica Composites for Methanol Nanocatalysis
}

\author{
S. Polarz, ${ }^{* \dagger}$ F. Neues, ${ }^{\ddagger}$ M. W. E. van den Berg, ${ }^{\ddagger}$ W. Grünert, ${ }^{\ddagger}$ and L. Khodeir ${ }^{\ddagger}$ \\ Contribution from the Technical University Berlin, Institute of Chemistry, Strasse des 17, \\ Juni 135, 10623 Berlin, Germany and Ruhr-University Bochum, Universitaestr. 150, \\ 44780 Bochum, Germany
}

E-mail: sebastian.polarz@tu-berlin.de.

\begin{abstract}
Methanol catalysis meets chemistry under confined conditions. Methanol is regarded as one of the most important future energy sources. $\mathrm{ZnO} / \mathrm{Cu}$ composite materials are very effective in heterogeneous catalysis for methanol production due to the so-called strong metal-support interaction effect (SMSI). Therefore, materials of superior structural design potentially representing model systems for heterogeneous catalysis are highly desired. Ultimately, such materials could help to understand the interaction between copper and zinc oxide in more detail than currently possible. We report the preparation of nanocrystalline, size-selected $\mathrm{ZnO}$ inside the pore system of ordered mesoporous silica materials. A new, liquid precursor for $\mathrm{ZnO}$ is introduced. It is seen that the spatial confinement significantly influences the chemical properties of the precursor as well as determines a hierarchical architecture of the final $\mathrm{ZnO} / \mathrm{SiO}_{2}$ nanocomposites. Finally, the ability of the materials to act as model systems in methanol preparation is investigated. The materials are characterized by a variety of techniques including electron microscopy, X-ray scattering, solidstate NMR, EPR, EXAFS, and Raman spectroscopy, and physisorption analysis.
\end{abstract}

\section{Introduction}

At the birth of heterogeneous catalysis it was already realized that catalytic activity scales with surface area. Thus, maximum dispersity of particles is of extraordinary importance. Obviously, this makes the production of nanoscaled catalysts very tempting. Thus, the use of nanoparticles is not new to heterogeneous catalysis at all. Increasing capability of refined analytical techniques begins to enable deepened understanding of the relation between catalytic activity and the real structure of heterogeneous catalysts on a molecular scale. ${ }^{1}$ The use of this knowledge is highly desired in order to improve existing catalyst materials by addressing structure-property relationships. It was recently discussed by Schloegl et al. ${ }^{2}$ that in order to control and determine functional properties of a catalyst, it becomes necessary that the material possesses hierarchical design with structural features on multiple length scales ranging from the molecular to macroscopic domain. Thus, a synergism of refined analytical techniques and a refined materials synthesis is highly desired. ${ }^{2}$ To differentiate this refined approach to "classical" heterogeneous catalysis, Schloegl proposes the expression nanocatalysis. $^{2}$

Synthetic routes for the preparation of complex inorganic materials with hierarchical architecture still stand at the beginning. To develop a mode of operation bridging between multiple length scales (the meso approach) ${ }^{3}$ and inorganic materials

\footnotetext{
Technical University Berlin.

$\doteqdot$ Ruhr-University Bochum.

(1) Bell, A. T. Science 2003, 299 (5613), 1688.

(2) Schlögl, R.; Abd Hamid, S. B. Angew. Chem., Int. Ed. 2004, 43, 1628.

(3) Antonietti, M.; Ozin, G. A. Chem. Eur. J. 2004, 10, 29.
}

synthesis is challenging. Such a materials preparation could, thus, be described as a "mesosynthesis" of materials. Application of this concept toward heterogeneous catalysis by inorganic particles means that besides nanosize the particles must be distributed in a hierarchical, spatial superstructure. In this respect, formation of inorganic nanoparticles inside the pores of nanoporous materials ${ }^{4}$ has been proven valuable. ${ }^{5}$ Mesoporous silica materials mostly of the MCM-41-type hosting polymers, ${ }^{6}$ noble metals, ${ }^{7}$ and semiconductors such as gallium nitride ${ }^{8}$ have been prepared successfully. Ideally the size and shape of those nanoparticles is determined by the pore size of the host matrix. ${ }^{9}$

However, concerning catalysis and other applications, not only are metallic particles interesting but nanoscaled metal oxides are as well. ${ }^{10}$ Interestingly, little attention has, so far, been devoted toward the controlled preparation of metal-oxide nanoparticles under confinement of mesopores. ${ }^{11,12}$ Three problems occur: Low loading degrees, lack of crystallinity, and lack of control over particle size. Small pores (typically ca. 3 $\mathrm{nm}$ for MCM-type materials) and low concentration of oxide

(4) Polarz, S.; Smarsly, B. J. Nanosci. Nanotechnol. 2003, 2, 581

(5) Polarz, S., Nanochemistry. In Enzyclopedia of Nanoscience and Nanotechnology; Nalwa, H. S., Ed.; American Scientific Publishers: 2004; p 179.

(6) Wu, C. G.; Bein, T. Science 1994, 264, 1757.

(7) Junges, U.; Jacobs, W.; Voigtmartin, I.; Krutzsch, B.; Schüth, F. Chem. Commun. 1995, 2283

(8) Winkler, H.; Birkner, A.; Hagen, V.; Wolf, I.; Schmechel, R.; Seggern, H. v.; Fischer, R. A. Adv. Mater. 1999, 11, 1444.

(9) Bronstein, L. M.; Polarz, S.; Smarsly, B.; Antonietti, M. Adv. Mater. 2001 $13,1333$.

(10) Weiss, W.; Schlögl, R. Top. Catal. 2000, 13, 75.

(11) Schüth, F.; Wingen, A.; Sauer, J. Microporous Mesoporous Mater. 2001 $44,465$.

(12) Köhn, R.; Fröba, M. Catal. Today 2001, 68, 227. 
precursors (often simple metal salts) excludes filling up pore volume even after multiple infiltrations. In addition, it seems that the interaction between the forming oxide and the oxidic host matrix $\left(\mathrm{SiO}_{2}\right)$ can be strong enough to hamper crystallization of the target oxide. ${ }^{13}$ This has been observed in attempts to produce $\mathrm{ZnO}$ in the pores of siliceous MCM-48, while the formation of $\mathrm{CuO}$ clusters could be achieved. ${ }^{12,13}$ It appears that, in particular, the formation of zinc oxide seems to be very difficult to achieve under spatial control of a mesoporous silica environment as either no nanocrystalline $\mathrm{ZnO}$ forms, ${ }^{14-16}$ the size of $\mathrm{ZnO}$ particles exceeds pore size significantly, or structural characterization is lacking completely. ${ }^{17-20}$

Methanol is industrially prepared by $\mathrm{Cu} / \mathrm{ZnO}$ composite catalysts. ${ }^{21}$ It was already recognized previously that methanol synthesis over $\mathrm{ZnO}$ catalysts is a structure-sensitive reaction highly dependent on the crystallinity of $\mathrm{ZnO}^{22}$ and that some sort of strong metal support interaction effect is responsible for the pronounced activity of copper with $\mathrm{ZnO}$ as a support. ${ }^{23,24}$ Thus, the preparation of a highly defined material containing nanocrystalline $\mathrm{ZnO}$ is very interesting with respect to obtaining new model systems for methanol catalysis.

In the current study we introduce a new liquid precursor for $\mathrm{ZnO}$ in combination with a refined nanoarchitecture of mesoporous silica materials. The preparation of size-selected, nanocrystalline $\mathrm{ZnO}$ particles supported by a bicontinuous porous framework is presented. In addition, the differences between nonconfined formation of $\mathrm{ZnO}$ is compared to the confined case inside differently sized pores.

\section{Results and Discussion}

The rational preparation of nanocrystalline $\mathrm{ZnO}$ hosted by silica mesopores involves the following steps:

Identification of a promising precursor for $\mathrm{ZnO}$;

Preparation of porous host matrixes;

Formation of $\mathrm{ZnO}$ under confinement.

Finally, materials are characterized and catalytically tested.

Development of a Liquid Precursor for $\mathrm{ZnO}$. Various methods exist for the preparation of $\mathrm{ZnO} .{ }^{25-28}$ For catalytic

(13) Tkachenko, O. P.; Klementiev, K. V.; Löffler, E.; Ritzkopf, I.; Schüth, F.; Bandyopadhyay, M.; Grabowski, S.; Gies, H.; Hagen, V.; Muhler, M.; Lu, L. H.; Fischer, R. A.; Grünert, W. Phys. Chem. Chem. Phys. 2003, 5, 4325.

(14) Becker, R.; Weiss, J.; Winter, M.; Merz, K.; Fischer, R. A. J. Organomet. Chem. 2001, 630, 253.

(15) Gies, H.; Grabowski, S.; Bandyopadhyay, M.; Grünert, W.; Tkachenko, O. P.; Klementiev, K. V.; Birkner, A. Microporous Mesoporous Mater 2003, 60 (1-3), 31 .

(16) Zhang, W.-H.; Shi, J.-L.; Wang, L.-Z.; Yan, D.-S. Chem. Mater. 2000, 12, 1408 .

(17) Cannas, C.; Mainas, M.; Musinu, A.; Piccaluga, G. Compos. Sci. Technol. 2003, 63, 1187.

(18) Lu, W. J.; Lu, G. Z.; Luo, Y.; Chen, A. P. J. Mol. Catal. A 2002, 188, 225

(19) Tang, G. Q.; Xiong, Y.; Zhang, L. Z.; Zhang, G. L. Chem. Phys. Lett. 2004, 395, 97.

(20) Ying, X.; Zhang, L. Z.; Tang, G. Q.; Zhang, G. L.; Chen, W. J. J. Lumin. 2004, $110,17$.

(21) Hansen, J. B. In Handbook of Heterogeneous Catalysis; Ertl, G., Knözinger, H., Weitkamp, J., Eds.; Wiley-VCH: New York, 1997; p 1856.

(22) Wilmer, H.; Kurtz, M.; Klementiev, K. V.; Tkachenko, O. P.; Grünert, W.; Hinrichsen, O.; Birkner, A.; Rabe, S.; Merz, K.; Driess, M.; Wöll, C.; Muhler, M. Phys. Chem. Chem. Phys. 2003, 5, 4736.

(23) Kurtz, M.; Bauer, N.; Buscher, C.; Wilmer, H.; Hinrichsen, O.; Becker, R.; Rabe, S.; Merz, K.; Driess, M.; Fischer, R. A.; Muhler, M. Catal. Lett. 2004, 92,49 .

(24) Gunter, M. M.; Ressler, T.; Bems, B.; Buscher, C.; Genger, T.; Hinrichsen, O.; Muhler, M.; Schlögl, R. Catal. Lett. 2001, 71, 37.

(25) Yan, C.-H.; Zhang, J.; Sun, L.-D. Encyclopedia Nanosci. Nanotechnol. 2004, $10,767$.

(26) Wang, Z. L. J. Phys.: Condens. Mater. 2004, 16, R829.

(27) Wang, Z. L. Mater. Today 2004, 7, 26.

(28) Look, D. C. Mater. Sci. Eng. B 2001, B80, 383. applications, zinc and copper are precipitated from simple salt solutions (mostly nitrates) by $\mathrm{Na}_{2} \mathrm{CO}_{3}$, and the precipitate is subsequently calcined (typically at $300-350{ }^{\circ} \mathrm{C}$ ). This, and the conditions of methanol catalysis, enables significant sintering of $\mathrm{ZnO}$, in particular, but also of copper. The subsequent decrease in surface area leads to an unwanted decrease in the catalytic activity. In addition, from the viewpoint of preparing $\mathrm{ZnO}$ inside nanometer-sized pores, it is not beneficial to work with diluted precursors such as aqueous solutions. From a particular volume infiltrated into the porous system, only a minor fraction will be the actual salt precursor. Second, the higher the boiling point of the solvent to be removed, the higher the risk to obtain an inhomogeneous distribution of the precursor in the material.

Therefore, an ideal precursor system for the preparation of $\mathrm{ZnO}$ in mesopores should transform into $\mathrm{ZnO}$ at low temperatures with a minimum amount of additional steps and the applicable concentration should be as high as possible. Recently we investigated the formation of $\mathrm{ZnO}$ from organometallic alkyl-alkoxy-zinc heterocubanes (alkyl = Me; alkoxy = $\left.\mathrm{O}^{\mathrm{i}} \mathrm{Pr}, \mathrm{O}^{\mathrm{t}} \mathrm{Bu}\right){ }^{29,30}$ These precursors are characterized by low thermolysis temperatures and high solubility in aprotic solvents. The heterocubanes are interesting because they represent, in a certain sense, a molecular "cut-out" of the $\mathrm{ZnO}$ structure. Unfortunately, the known precursors of this type evaporate already at low temperature. Once infiltrated, undesired sublimation from the porous material can be expected. Therefore, a new precursor was prepared by reaction of dimethlyzinc with methoxyethanol in dry toluene (detailed procedure is given in the Supporting Information SI1).

$$
x \mathrm{Zn}\left(\mathrm{CH}_{3}\right)_{2}+x \mathrm{HOCH}_{2} \mathrm{CH}_{2} \mathrm{OCH}_{3} \stackrel{-x \mathrm{CH}_{4}}{\longrightarrow}
$$

The precursor is available even on the multigram scale. Interestingly, the resulting $\left[\mathrm{CH}_{3} \mathrm{ZnOCH}_{2} \mathrm{CH}_{2} \mathrm{OCH}_{3}\right]_{x}$ alkyl-zinc alkoxide possesses not only low vapor pressure, it can be treated even at $P=10^{-3}$ mbar without evaporation, but it is also liquid at room temperature $\left(\mathrm{mp} \approx-15^{\circ} \mathrm{C}\right)$. However, it was not possible to determine the nuclearity $x$ of the cluster by NMR or MS (see Supporting Information), so its crystal structure was determined by applying in-situ crystal breeding inside a quartz capillary at low temperature. It could be revealed that the tetrameric heterocubane $1\left[\mathrm{CH}_{3} \mathrm{ZnOCH}_{2} \mathrm{CH}_{2} \mathrm{OCH}_{3}\right]_{4}$ was obtained (Figure 1).

The liquid character of $\mathbf{1}$ is a real advantage. The maximum degree of loading of the mesoporous matrix is no further determined by any saturation concentration, but now starting from $100 \%$ any lower infiltration degree can be adjusted by simple dilution (e.g., in dry pentane).

Preparation of Porous Host Matrixes. True liquid-crystal templating, first developed by Goeltner et al., ${ }^{31}$ was used for preparation of the mesoporous materials used in this study. Pore sizes of up to $15 \mathrm{~nm}$ can be obtained by using lyotropic blockcopolymer phases as templates. ${ }^{32-34}$ We were recently able to extend this approach by introducing a facile method to prepare

(29) Polarz, S.; Roy, A.; Merz, M.; Halm, S.; Schröder, D.; Scheider, L.; Bacher, G.; Kruis, F. E.; Driess, M. Small 2005, 1, 540.

(30) Ischenko, V.; Polarz, S.; Grote, D.; Stavarache, V.; Fink, K.; Driess, M. Adv. Funct. Mater. 2005, in print.

(31) Attard, G. S.; Glyde, J. G.; Göltner, C. G. Nature 1995, 378, 366. 

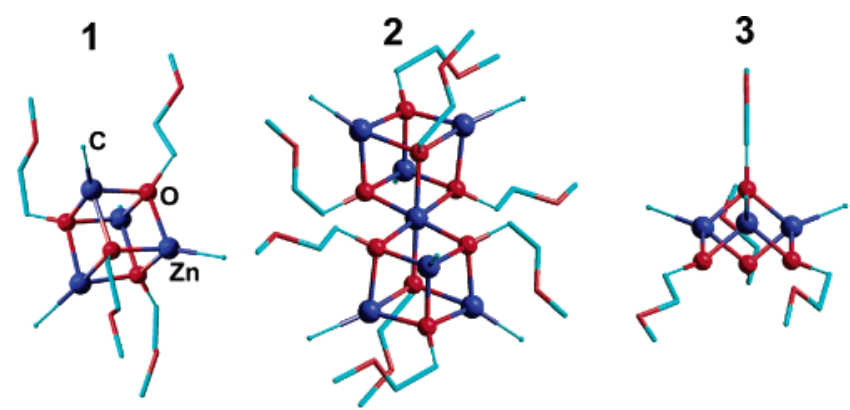

Figure 1. Single-crystal X-ray structures (see SI1) of precursor $\mathbf{1},\left[\mathrm{CH}_{3-}\right.$ $\left.\mathrm{ZnOCH}_{2} \mathrm{CH}_{2} \mathrm{OCH}_{3}\right]_{4}$ and its partial hydrolysis product 2, $\left[\left(\mathrm{CH}_{3}\right)_{7} \mathrm{Zn}_{7-}\right.$ $\left.\left(\mathrm{OCH}_{2} \mathrm{CH}_{2} \mathrm{OCH}_{3}\right)_{8}\right]$, and structure of the tridentate cluster ligand $\mathbf{3}$, $\left[(\mathrm{CH})_{3} \mathrm{Zn}_{3}\left(\mathrm{OCH}_{2} \mathrm{CH}_{2} \mathrm{OCH}_{3}\right)_{4}\right]^{-}$. $\mathrm{H}$ atoms not shown.

porous materials with any desired pore size in the range 1.5$10 \mathrm{~nm} .{ }^{35,36}$ This method uses mixtures of chemically equal but differently sized amphiphiles as template systems. The approach is applicable to any amphiphilic system possessing PEO as the hydrophilic block (Brij-surfactants alkyl-PEO, poly(styrene)$\mathrm{PEO}$, and $\mathrm{PEO}-\mathrm{PPO}-\mathrm{PEO})$. The method for preparation of those materials is reported in detail in ref 35 . For this study we prepared materials with the following pore sizes: 3.5 (using Brij 35), 4 (using Brij 58), 4.5 (using $\mathrm{S}_{10} \mathrm{E}_{10}$ ), 5 (using Pluronic P123), 6.5, 7.7 (using mixtures of Pluronics P123 and F127), and $9.5 \mathrm{~nm}$ (using Pluronic F127). In addition, a porous material of $2 \mathrm{~nm}$ pore size was prepared using methylated- $\beta$-cyclodextrins as a template. ${ }^{36,37} \mathrm{SBA}-15^{32}$ comes closest to the materials used in this study, and indeed, the preparation method is very similar. However, materials with cylindrical pores appear less favorable for catalytic applications because access to functional particles inside the pore system can be easily blocked. Although microporosity induced by the PEO chains in the template ${ }^{35,38,39}$ already grants additional access to the pores, we are instead interested in a three-dimensional, bicontinuous pore system. This can be achieved with all of the templates mentioned if the preparation is performed under nonequilibrium conditions. ${ }^{35,36}$ This leads to a lower degree of long-range order, thus to "wormhole"-type mesoporous materials (Figure 2). Nevertheless, pore-size distributions are very narrow. ${ }^{35}$ The resulting structure can be related best to the transition in the template phase between dense micellar packing to the cylindrical phase (casted in SBA-15), thus possessing some similarities to the bicontinuous pore system of MCM- $48 .{ }^{40}$ In most cases, a material with $5 \mathrm{~nm}$ pores was used as a model system (Figure 2).

These materials are therefore promising model hosts to investigate chemistry under confined conditions. ${ }^{41}$ In addition, these materials exhibit rather thick pore walls with an average diameter $\approx 4 \mathrm{~nm}$ (Figure 2). The condensation degree is quite high, as expected for calcined silica samples (see SI2). Thus,

(32) Zhao, D.; Feng, J.; Huo, Q.; Melosh, N.; Fredrickson, G. H.; Chmelka, B. F.; Stucky, G. D. Science 1998, 279, 548.

(33) Göltner, C. G.; Henke, S.; Weißenberger, M. C.; Antonietti, M. Angew. Chem. 1998, 110, 633.

(34) Thomas, A.; Schlaad, H.; Smarsly, B.; Antonietti, M. Langmuir 2003, 19, 4455.

(35) Smarsly, B.; Polarz, S.; Antonietti, M. J. Phys. Chem. B 2001, 105, 10473.

(36) Polarz, S.; Antonietti, M. Chem. Commun. 2002, 2593.

(37) Polarz, S.; Smarsly, B.; Bronstein, L.; Antonietti, M. Angew. Chem., Int. Ed. 2001, 40, 4417 .

(38) Smarsly, B.; Goltner, C.; Antonietti, M.; Ruland, W.; Hoinkis, E. J. Phys. Chem. B 2001, 105, 831 .

(39) Göltner, C. G.; Smarsly, B.; Berton, B.; Antonietti, M. Chem. Mater. 2001 $13,1617$.

(40) Alfredsson, V.; Anderson, M. W. Chem. Mater. 1996, 8, 1141-1146.

(41) Thomas, A.; Polarz, S.; Antonietti, M. J. Phys. Chem. B 2002, 107, 5081.

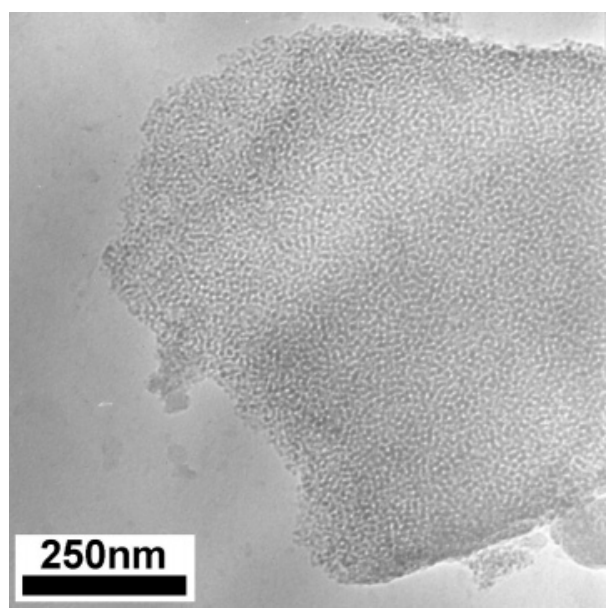

Figure 2. TEM image of a "wormhole" mesoporous silica material with a pore diameter of $5 \mathrm{~nm}$.

the strength of the pore walls should to be sufficient to confine the growth of $\mathrm{ZnO}$ particles inside. Furthermore, the pore wall is characterized by a significant number of silanol groups.

Another advantage of the materials introduced here is that they are obtained as granular monoliths (see SI3) and not as powders as, for instance, MCM materials. Therefore, the external surface area is negligible in comparison to the internal surface of the pore system. Furthermore, liquid infiltration, as used here, is very simple to manage. The monoliths are given inside the precursor solution, via capillary forces the solution is drawn into the pore system quickly, the monolith can be removed, and the external surface is washed. One can be sure that all precursor is definitely inside the pore system and that all effects that may emerge are caused by confinement effects.

Formation of $\mathrm{ZnO}$ under Confinement. The transformation of the heterocubane $\mathbf{1}$ to zinc oxide in the nonconfined situation was always taken as the reference state. The solid-state thermolysis of $\mathbf{1}$ in an atmosphere containing $80 \mathrm{vol} \% \mathrm{Ar}$ and 20 vol $\% \mathrm{O}_{2}$ was investigated by thermogravimetric analysis first. The samples were heated to a final temperature of 800 ${ }^{\circ} \mathrm{C}$, leading to white powder. No carbon contaminations were present according to elemental analysis.

Figure 3a shows only the differential thermal analysis (DTG) traces of the measurements. The precursor 1 was treated at three different heating rates $R_{1}=1 \mathrm{~K} \mathrm{~min}^{-1}, R_{2}=5 \mathrm{~K} \mathrm{~min}^{-1}$, and $R_{3}=10 \mathrm{~K} \mathrm{~min}^{-1}$ in order to gain an impression of the kinetic factors influencing the transformation process. The precursor starts to decompose practically in one step already at temperatures as low as $152^{\circ} \mathrm{C}$, and the point of strongest thermolysis is located at $218{ }^{\circ} \mathrm{C}$ with a small shoulder at $240{ }^{\circ} \mathrm{C}$ if the TGA experiment is performed under conditions close to equilibrium $\left(R_{1}\right)$. The DTG trace is smeared out for higher thermolysis rates; two separate steps can be identified at $219{ }^{\circ} \mathrm{C}$ and ca. $300{ }^{\circ} \mathrm{C}$ for $R_{2}$. For the fastest heating rate $\left(R_{3}\right)$ an extremely broad thermolysis phase can be observed, and the first minimum of the DTG trace (which accounts for a maximum in thermolysis) is shifted to ca. $200{ }^{\circ} \mathrm{C}$. In summary, faster heating rates lead to nonequilibrium conditions and complete thermolysis of precursor $\mathbf{1}$ only at higher temperatures.

The precursor was infiltrated, and under identical conditions TGA was recorded in a second row of experiments. Successful infiltration with the heterocubane $\mathbf{1}$ was monitored by FT-Raman 

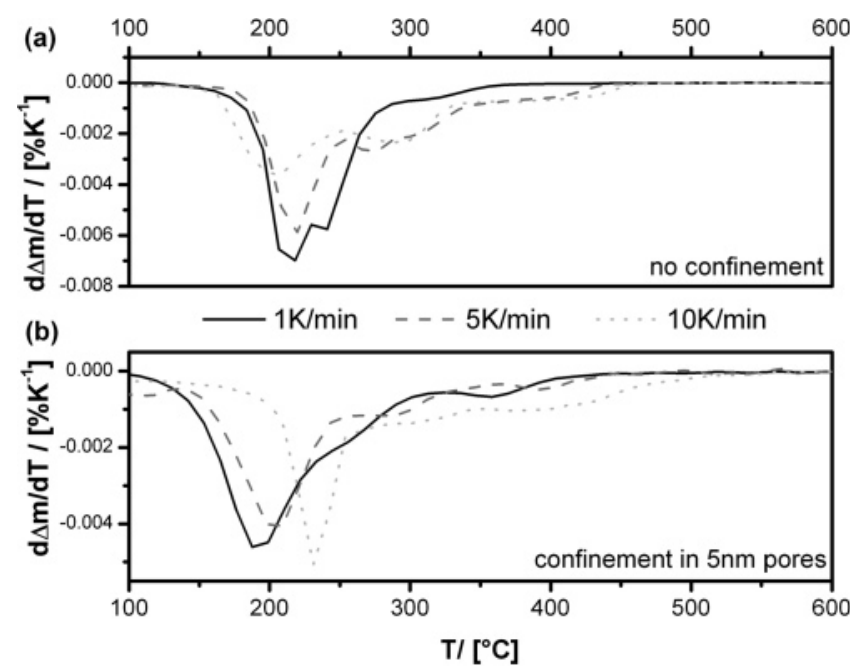

Figure 3. DTG traces of the thermolysis of $\mathbf{1}$ for three different heating rates: (a) nonconfined system as a reference and (b) thermolysis under confinement.

spectroscopy (see SI4). Furthermore, if loaded monoliths were extracted with dry hexane, not only was liquid 1 recovered, but also a minor fraction of a new, solid compound of slightly different chemical shifts in NMR (see SI5) was found. Singlecrystal X-ray structure determination revealed that this new compound is a heptameric cluster $\left[\left(\mathrm{CH}_{3}\right)_{7} \mathrm{Zn}_{7}\left(\mathrm{OCH}_{2} \mathrm{CH}_{2}-\right.\right.$ $\left.\mathrm{OCH}_{3}\right)_{8}$ ], 2 (Figure 1). It is interesting to note that 2 represents a coordination compound of one octahedral $\mathrm{Zn}^{2+}$ with two tridentate $\left[(\mathrm{CH})_{3} \mathrm{Zn}_{3}\left(\mathrm{OCH}_{2} \mathrm{CH}_{2} \mathrm{OCH}_{3}\right)_{4}\right]^{-}, 3$, metal-cluster ligands (Figure 1). Thus, 2 can be obtained as the byproduct of partial hydrolysis of $\mathbf{1}$. Because the porous silica materials were carefully dried in a vacuum at $150{ }^{\circ} \mathrm{C}$ for $24 \mathrm{~h}$, it is rather unlikely that this hydrolysis results from water adsorbed in the pore system. ${ }^{29} \mathrm{Si}-\mathrm{MAS}$ NMR (see SI2) indicates that the $\mathrm{Zn}-$ $\mathrm{CH}_{3}$ functionality in $\mathbf{1}$ is able to react with silanol groups to produce surface-bound $\mathrm{Si}-\mathrm{O}-\mathrm{Zn}$ species. The byproduct of this surface reaction is obviously the cluster $\mathbf{2}$. Nevertheless, it can be concluded that the majority of $\mathbf{1}$ can be successfully infiltrated into the pore system without modification. Compared to the nonconfined thermolysis reaction of $\mathbf{1}$, in the case of confining 1 to $5 \mathrm{~nm}$ pores, complete thermolysis is reached only at higher temperatures (Figure 3b). This effect is strongest for $R_{3}$, and it can be concluded that the growth of $\mathrm{ZnO}$ does not take place under equilibrium conditions in mesopores. As a consequence, the $\mathrm{ZnO}$ formed under confinement possesses significant differences in fine structure, most importantly the occurrences of oxygen defects sites (see SI6) as proven by EPR spectroscopy. More details about oxygen-deficient $\mathrm{ZnO}$ are reported elsewhere. $^{29,30}$

The samples contain on the order of $40 \% \mathrm{ZnO}$ after thermolysis. Interestingly, and unlike the nonconfined situation, the point of maximum thermolysis is shifted from $190{ }^{\circ} \mathrm{C}$ for $R_{1}$ to $204{ }^{\circ} \mathrm{C}$ for $R_{2}$ to $231{ }^{\circ} \mathrm{C}$ for $R_{3}$, and simultaneously, the width of the corresponding DTG signal decreases. This indicates that the thermolysis of the cubane differs significantly under confined conditions. Similar behavior is also observed for other precursors not mentioned in this study, so we think that this is a more general feature. In particular, the shift of the point of strongest thermolysis toward lower temperatures $(\Delta T \approx-30$ ${ }^{\circ} \mathrm{C}$ ) at conditions closest to equilibrium $\left(R_{1}\right)$ is remarkable. This effect cannot be explained by kinetic factors alone. One possible (a)

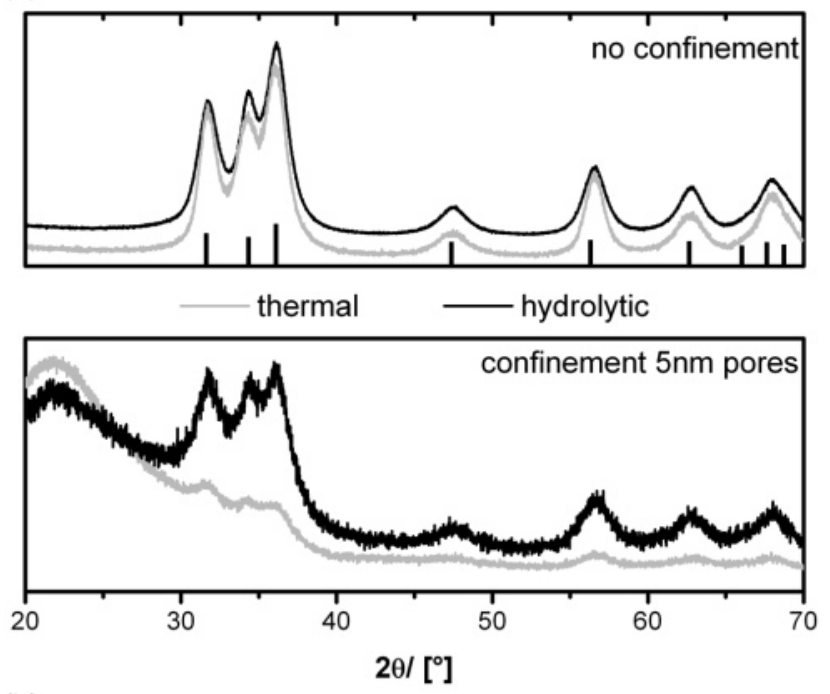

(b)

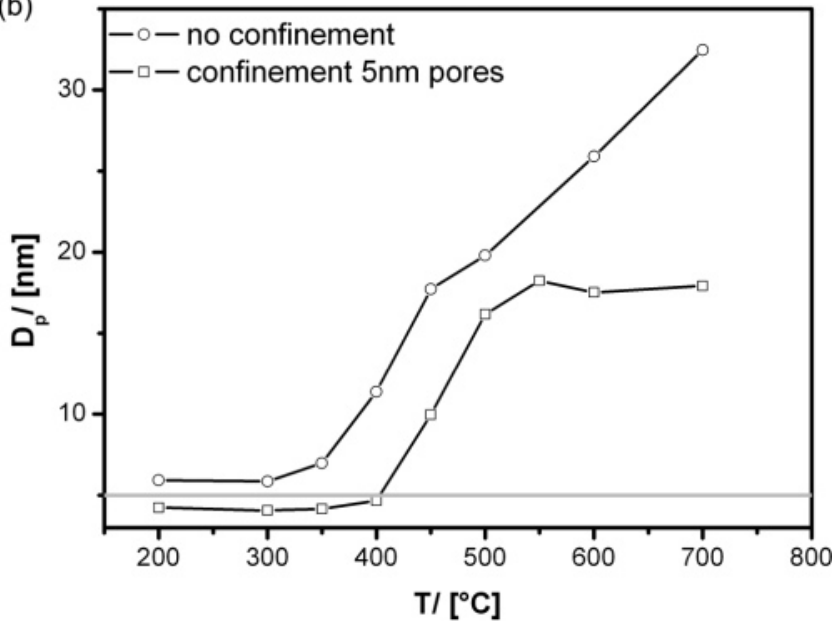

Figure 4. (a) Comparison of the hydrolytic and thermal route to obtain $\mathrm{ZnO}$ from precursor 1. PXRD patterns are shown for the preparation under nonconfinement (upper diffractogram) and confinement conditions (lower diffractogram). (b) Temperature dependence of particle size obtained from PXRD data.

explanation could be that the number of molecules inside one pore is restricted, as we showed earlier for the formation of excimers in porous matrixes. ${ }^{41}$ These systems, thus, have to be considered from the viewpoint of statistical thermodynamics. A Boltzmann distribution does not account for systems containing very few molecules. On a molecular basis, one may speculate that the energy (e.g., thermal energy) once injected into the molecules cannot be dispensed to neighbors, but all the energy is directly used for the thermolysis of the precursor. This difference in statistics may account for lower thermolysis temperatures.

It is known from these types of precursors that they can be converted to $\mathrm{ZnO}$ also hydrolytically. This was tested by aging the materials containing precursor $\mathbf{1}$ in an atmospheric chamber at $60{ }^{\circ} \mathrm{C}$ and $50 \%$ room humidity. For comparison, a separate set of samples was prepared by thermolysis with a final temperature of $350{ }^{\circ} \mathrm{C}$ and equilibrium heating rate of $R_{1}=1$ $\mathrm{K} \min ^{-1}$. The samples were investigated by powder X-ray diffraction (PXRD; Figure 4a). The observed diffraction patterns can be assigned to hexagonal $\mathrm{ZnO}$. Particle sizes $\mathrm{D}$ were calculated from the full-width half-maximum (fwhm) of PXRD patterns using the isolated reflex centered at $56.6^{\circ} 2 \theta .^{42}$ It is 

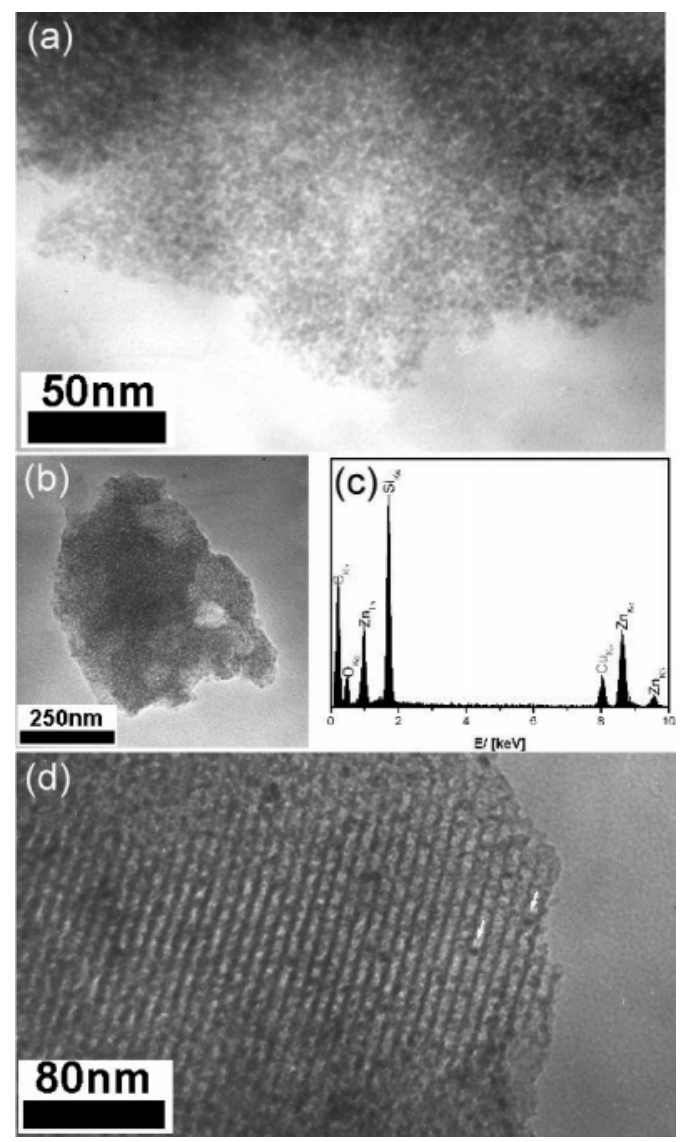

Figure 5. (a) TEM micrograph of $\mathrm{ZnO}$ particles obtained for the preparation under nonconfinement conditions. (b) TEM image of the $\mathrm{ZnO} / \mathrm{SiO}_{2}$ nanocomposite at a position with the wormhole pore system, and (c) EDX spectrum of this spot. (d) TEM micrograph of a position with cylindrical pore system.

seen that for the preparation of $\mathrm{ZnO}$ under unrestricted conditions, thermolysis and hydrolysis lead to $\mathrm{ZnO}$ particles of nearly the same size. However, hydrolysis seems to be much more favorable for the preparation of nanocrystalline particles inside the $5 \mathrm{~nm}$ mesoporous host (Figure 4b). The diffractions arising from $\mathrm{ZnO}$ in relation to the broad signal at $21.9^{\circ} 2 \theta$ arising from amorphous $\mathrm{SiO}_{2}$ are much higher in intensity for the hydrolytic preparation of $\mathrm{ZnO}$.

In addition, both samples, nonconfined (nc) and confined to $5 \mathrm{~nm}$ (c5), prepared by hydrolysis in the atmospheric chamber can be compared to each other. The difference in particle diameter for the as-prepared samples is significant but small, $D_{\mathrm{nc}}=5.7 \mathrm{~nm}$ compared to $D_{\mathrm{c} 5}=4.6 \mathrm{~nm}$. However, as expected, the dispersity of the $\mathrm{ZnO}$ particles is very different. TEM micrographs show that the particles formed under nonconfined conditions form large agglomerates of a huge number of particles (Figure 5a). In comparison to the porous material not containing any $\mathrm{ZnO}$ (Figure 2), the sample prepared for c5 is also characterized by the "wormhole" pore system. The imaging contrast seems to be enhanced in comparison to the pure silica sample, and EDX measurement on the material proves that the sample contains $\mathrm{Zn}$ in the expected amount (Figure 5c). However, even at higher magnifications it was practically impossible to image individual $\mathrm{ZnO}$ particles inside the silica mesopores when places of the "wormhole" pore system were

(42) Lifshin, E. X-ray Characterization of Materials; Wiley-VCH: Weinheim, 1999. (a)
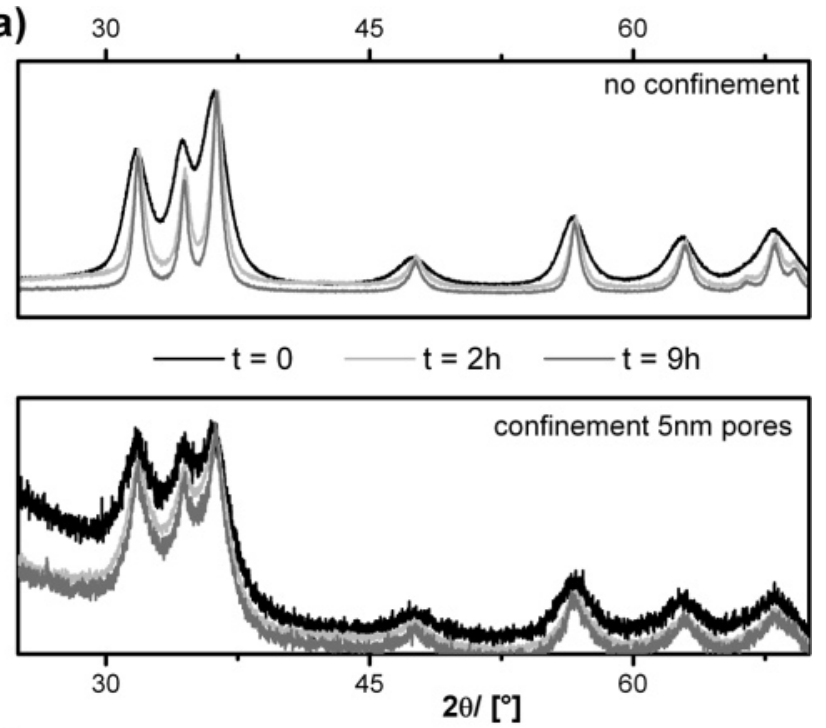

(b)

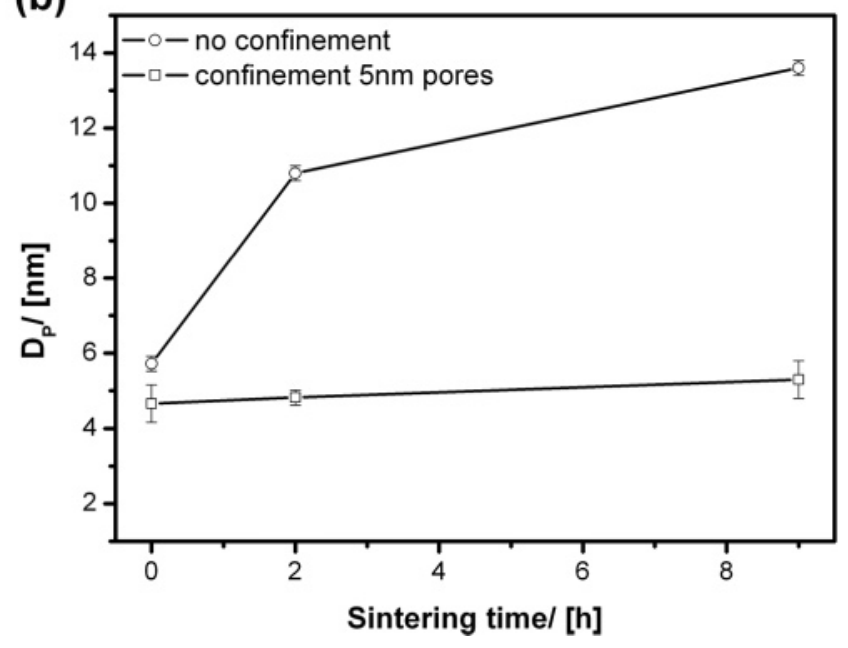

Figure 6. (a) PXRD patterns obtained after holding $\mathrm{ZnO}$ particles for different times at $350{ }^{\circ} \mathrm{C}$ for the nonconfined case (upper diffractogram) and when the particles are confined to the pore system. (b) Resulting correlation between particle size and sintering time.

investigated. However, the imaging contrast between the pore surfaces and the pore interior enhances when the hexagonal phase of SBA-15 $5^{32}$ was searched (which makes about 5-10\% of our samples). At those places it was indeed possible to clearly image individual $\mathrm{ZnO}$ particles confined to the pore volume (Figure 5d).

This indicates that the pores effectively confine the growth of the $\mathrm{ZnO}$ particles. With respect to heterogeneous catalysis, the dispersion stability of the prepared $\mathrm{ZnO}$ particles under real catalysis conditions is of further importance. Methanol catalysis is often performed at temperatures around $300{ }^{\circ} \mathrm{C}$, and it is known that sintering of $\mathrm{ZnO}$ is a major problem because the lower surface area results in lower catalytic activity. ${ }^{21}$ Consequently, the as-prepared samples were exposed to a temperature of $350{ }^{\circ} \mathrm{C}$ and sintered for 2 and $9 \mathrm{~h}$, respectively. PXRD patterns from resulting samples are shown in Figure 6a. Significant sintering of particles is observed for the nonconfined case indicated by the succeeding narrowing of the diffraction patterns. After $2 \mathrm{~h}$ particle growth to $10.8 \mathrm{~nm}$ and after $9 \mathrm{~h}$ even to $13.6 \mathrm{~nm}$ occurred. In contrast, the porous matrix confines the growth of the $\mathrm{ZnO}$ particles even under prolonged time of 
high-temperature treatment. Slow particle growth from initially $4.6 \mathrm{~nm}$ to finally $5.3 \mathrm{~nm}$ is seen, but within the error the particle size is still consistent with pore restriction.

However, the excellent dispersion of the $\mathrm{ZnO}$ particles hosted by the silica mesopores is not stable at temperatures higher than $400{ }^{\circ} \mathrm{C}$. It is seen from PXRD that above this point particles exceed the limitation of pores, although their growth is still slower compared to the nonconfined reference system (Figure 4b). TEM investigations indicate massive disintegration of the mesostructure, and EDX measurements show the occurrence of zinc- and silicon-containing particles but also of particles containing only zinc as a metal (both not shown). The obvious destruction of the $\mathrm{ZnO} / \mathrm{SiO}_{2}$ nanocomposite and partial demixing into the single components at high temperatures is surprising because the mesoporous silica by itself is stable to temperatures above $800{ }^{\circ} \mathrm{C}$. The observed restructuring process is yet not understood in detail, but eventually it may be catalyzed by the possible formation of zinc silicate. Although in PXRD no presence of $\mathrm{Zn}_{2} \mathrm{SiO}_{2}$ is seen, a broad shoulder at $-70 \mathrm{ppm}$ is found in ${ }^{29} \mathrm{Si}-\mathrm{MAS} \mathrm{NMR}$, indicating formation of amorphous $\mathrm{Zn}-\mathrm{O}-\mathrm{Si}$ motives (see SI2). ${ }^{17,43}$

Nevertheless, having proven the stability and confinement ability of the mesoporous silica at temperatures below $400{ }^{\circ} \mathrm{C}$, now the materials with differently sized pores were infiltrated with precursor $\mathbf{1}$, and $\mathrm{ZnO}$ was prepared inside the pores hydrolytically and sintered at $150{ }^{\circ} \mathrm{C}$ afterward. The resulting materials were investigated by PXRD and EXAFS (Figure 7).

Figure 7 a shows the relation between the host pore size $\left(D_{\text {conf. }}\right)$ and the diameter of the resulting $\mathrm{ZnO}$ particles formed under confinement. It is seen that a clear correlation exists: the larger the pores, the larger the $\mathrm{ZnO}$ particles are allowed to get. Although a linear correlation between $D_{\mathrm{p}}$ and $D_{\text {conf. }}$ is found, most of the obtained samples contain particles significantly smaller than the maximum diameter allowed from the viewpoint of pore size (1:1 relation). Even if the total volume of the mesopore is filled with precursor, as in this case, the decrease can be attributed to the volume decrease involved in the transformation of [MeZnOEtOMe $]_{4}$ to $\mathrm{ZnO}$ due to loss of the organic groups. The determination of $\mathrm{ZnO}$ particle size from XRD for the host matrix with $2 \mathrm{~nm}$ was complicated by the broad diffraction pattern (Figure 7b), resembling those of nearly amorphous $\mathrm{ZnO}$. However, EXAFS spectra confirmed the results obtained from PXRD. The coordination number of the first $\mathrm{Zn}$ shell (at $2.9 \AA$, uncorrected, see Figure 7c) was found to double (from 1.8 to 3.5 ) when the pores size was increased from 1.8 to $9.5 \AA$ (see Figure $7 \mathrm{~b}$ ), indicating that the crystallite size has increased. $\mathrm{ZnO}$ prepared in very small confinements is characterized by much lower long-range order.

A question that, yet, remains unanswered is whether despite the high degree of $\mathrm{ZnO}$ loading the obtained samples are suitable for heterogeneous catalysis. It has to be ensured that the $\mathrm{ZnO}$ particles are accessible. Therefore, the samples were also characterized by $\mathrm{N}_{2}$-physisorption measurements (Figure 8). In comparison to the starting materials with ca. $5 \mathrm{~nm}$ pores, a decrease in pore volume is seen. However, such a decrease is expected because the $\mathrm{ZnO}$ particles are located in the pore volume as demonstrated above. Indeed, the decrease in mesopore volume of ca. $32 \%$ fits quite well to the $\mathrm{ZnO}$ loading of

(43) Roy, A.; Polarz, S.; Rabe, S.; Rellinghaus, B.; Zahres, H.; Kruis, F. E.; Driess, M. Chem. Eur. J. 2004, 10, 1565.
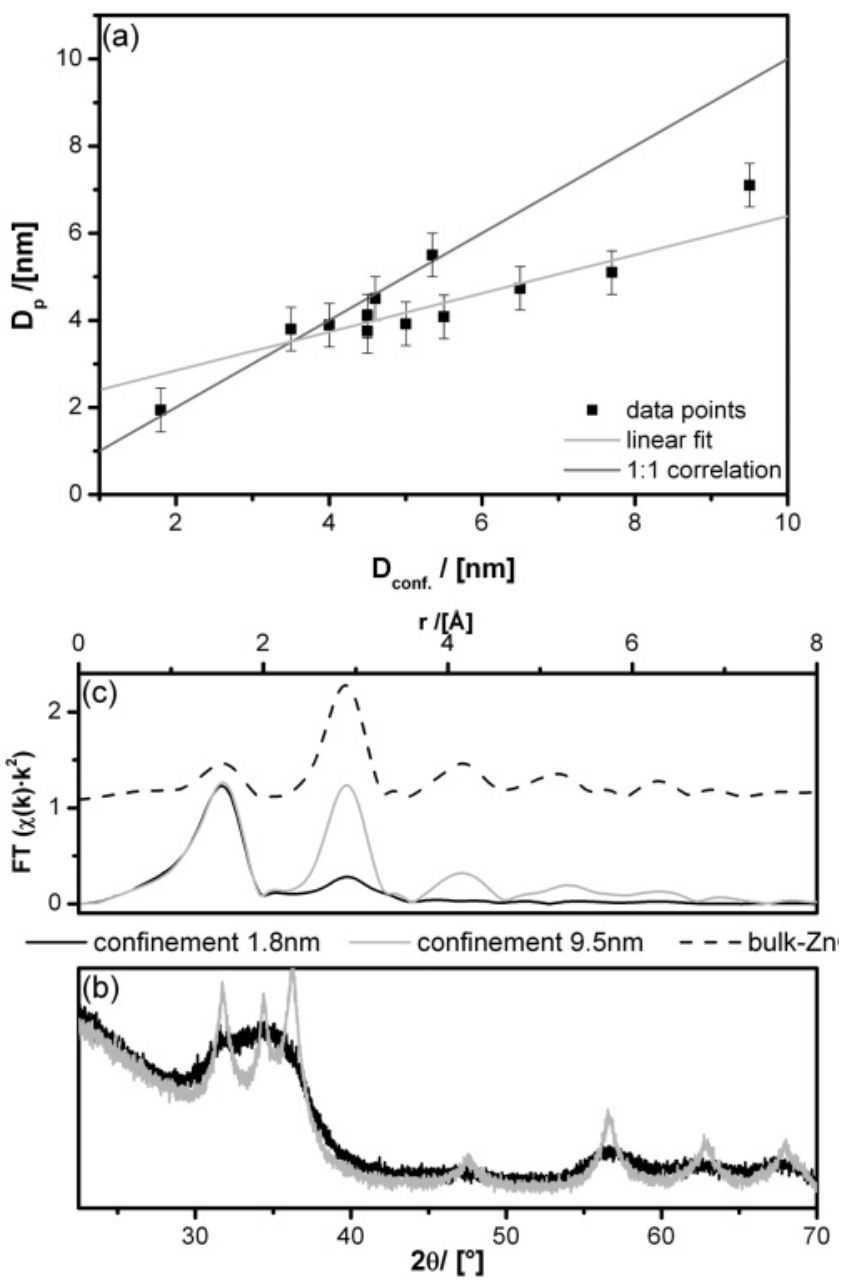

Figure 7. (a) Correlation between the pore size of the host matrix and the resulting particle size of generated $\mathrm{ZnO}$. (b and c) PXRD and EXAFS spectra of two materials with embedded $\mathrm{ZnO}$ particles into two differently sized confinement systems.

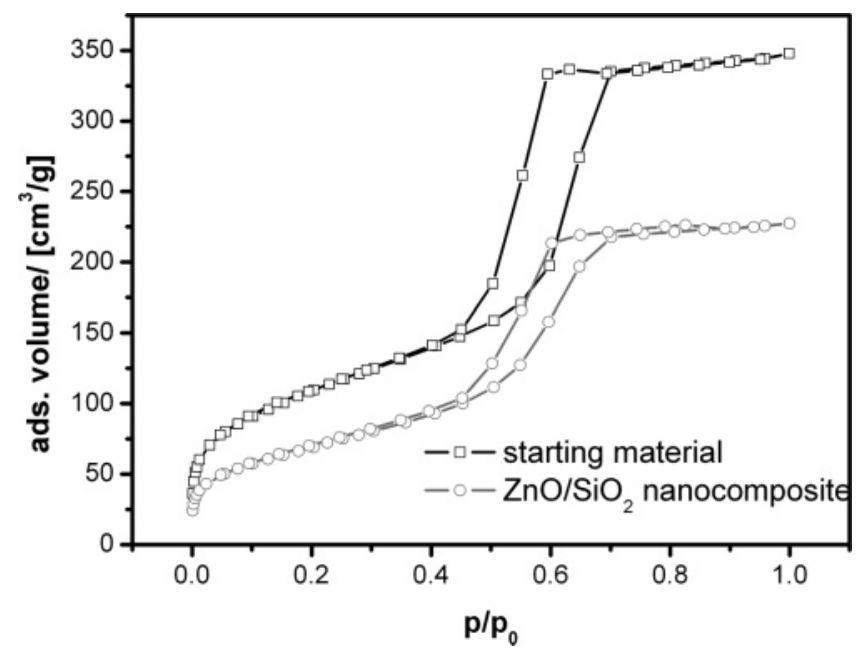

Figure 8. $\mathrm{N}_{2}$ physisorption isotherms for the "empty" mesoporous silica of pore size $\approx 5 \mathrm{~nm}$ and after formation of $\mathrm{ZnO}$ particles inside the material.

this sample (ca. 40\%) considering the higher density of $\mathrm{ZnO}$ compared to $\mathrm{SiO}_{2}$. In addition, the decrease in adsorbed volume at low $p / p_{0}$ indicates the blocking of micropores. Nevertheless, it can be seen that the pore system and the $\mathrm{ZnO}$ particles inside are still accessible. Furthermore, a lower degree of loading, higher pore volumes and higher surface areas, can be obtained 

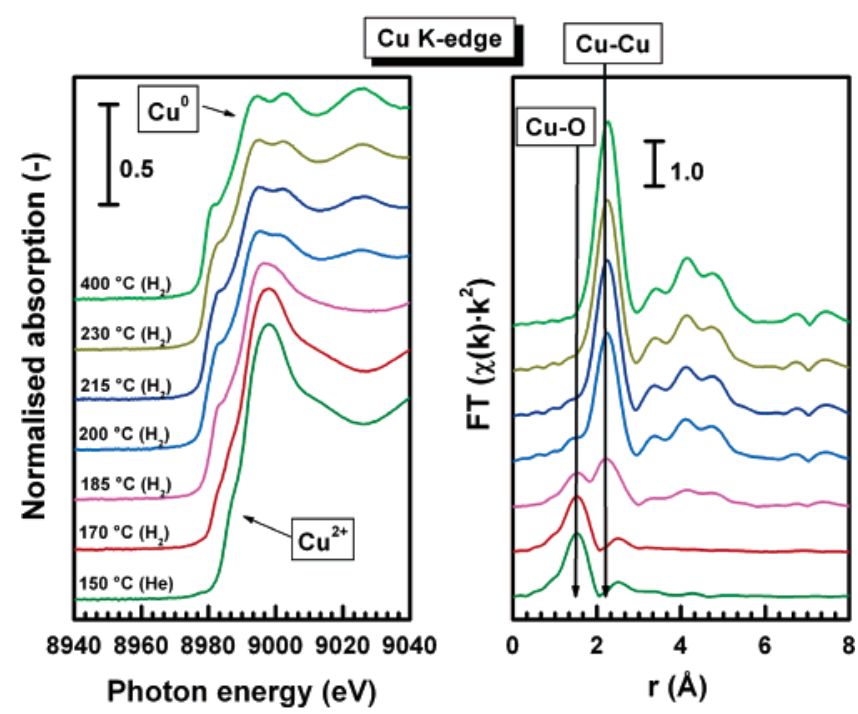

Figure 9. $\mathrm{Cu}$ K-edge $\mathrm{X}$-ray absorption spectra of the in-situ reduction of a $\mathrm{Cu} / \mathrm{ZnO}$ nanocatalyst hosted in silica with a $50 \AA$ pore size. Shown is the $\mathrm{Cu}$ edge with copper oxidation states indicated in the XANES (left). The emergence of metallic copper is seen in the EXAFS as well (right).

when a dilute solution is used for infiltration of the porous material as mentioned above.

Investigation of Catalytic Properties. To test the applicability of our materials as catalysts in methanol synthesis, in a preliminary experiment a $\mathrm{ZnO}$-containing mesoporous silica monolith was further infiltrated with a saturated copper acetate solution. The effect of the nanoarchitecture on the reduction of $\mathrm{Cu}^{2+}$ was studied in a unique experiment combining temperature-programmed reduction (TPR) with in-situ XAS (for experimental details, see ref 13 and SI7). Compared to other systems prepared using aqueous salt precursors, it is seen that reduction of $\mathrm{Cu}^{2+}$ starts at significantly lower temperatures. The reduction progresses as temperature increases, with an intermediate state observed at $185^{\circ} \mathrm{C}$, until at $200^{\circ} \mathrm{C}$ a completely reduced copper state is seen (Figure 9). This may reflect, similar to the reduced thermolysis temperatures of the $\mathrm{ZnO}$ precursors, the impact of the porous environment on the chemical behavior of confined guests. Finally, the samples were catalytically tested after reduction of the catalyst at $448 \mathrm{~K}$ in dilute $\mathrm{H}_{2}$. Methanol activity was measured at atmospheric pressure and $493 \mathrm{~K}$ (see SI8). Considering the low copper loading of only $0.8 \%$ achieved by this first experiment, the catalytic activity is reasonable. Optimization of the copper loading is beyond the scope of the current manuscript and will be presented elsewhere.

\section{Conclusion}

Ordered mesoporous materials of wormhole structure were used for the preparation of nanocrystalline $\mathrm{ZnO}$ particles. The spatial confinement of the mesopores enabled restricting the growth of $\mathrm{ZnO}$ to the size of the pores and enhancing the dispersity of the particles even under elevated temperatures and in the long run. Materials of very high $\mathrm{ZnO}$ content could be achieved by use of a new liquid precursor. This precursor was characterized by the preorganization of $\mathrm{ZnO}$ on a molecular scale via a heterocubane architecture. Interestingly, it was seen that the thermolysis behavior of this precursor was significantly affected by the spatial confinement. A shift of the main thermolysis step toward lower temperature was observed even at conditions close to equilibrium. This unusual behavior can be explained most likely by the small number of precursor molecules present inside a mesopore in comparison to the bulk, liquid precursor. After thermolysis $\mathrm{ZnO}$-silica nanocomposites with a maximum $\mathrm{ZnO}$ content of ca. $50 \mathrm{wt} \%$ were prepared while the particles remain highly accessible due to the "wormhole" architecture of the pore system. Finally, we tested the capability of the presented materials to be used as model systems for $\mathrm{Cu} / \mathrm{ZnO}$ catalysts for methanol preparation. Porous $\mathrm{Cu}^{2+}$ and $\mathrm{ZnO}$-containing materials could be prepared. It was seen that the intimate contact of copper and zinc oxide led to a significant decrease of the reduction temperature of $\mathrm{Cu}^{2+}$. The materials obtained were also active in methanol production. However, the detailed study of the ternary systems $\mathrm{Cu} / \mathrm{ZnO}$ / meso- $\mathrm{SiO}_{2}$ is beyond the scope of this manuscript and will be presented elsewhere.

Acknowledgment. The German research foundation (DFG) is gratefully acknowledged for funding (Emmy-Noether program; SFB 558). We thank D. Grote for measuring EPR-spectra. Dr. K. Merz is gratefully acknowledged for single-crystal structure determination.

Supporting Information Available: Experimental procedure for the preparation of precursors, and single-crystal data (SI1); ${ }^{29} \mathrm{Si}$-MAS NMR spectra (SI2); Photographic image of monolithic silica materials (SI3); FT-Raman spectra of infiltration process (SI4); ${ }^{1} \mathrm{H}$ NMR spectra of infiltration process (SI5); $\mathrm{X}$-band EPR spectra of $\mathrm{ZnO}$ containing mesoporous silica (SI6); experimental details for EXAFS measurements (SI7); experimental details for catalytic measurements (SI8). This material is available free of charge via the Internet at http://pubs.acs.org.

JA0516514 